\title{
Africa in Transition.*
}

$\mathrm{D}$

RING the last fifty years, Africa has passed from the age of the pioneer and of geographical exploration, and has become a mosaic of more or less organised territories, controlled by European Powers. But although Africa has made such an advance that Nairobi, where forty years ago no vestige of human life was to be seen, is now a modern city with hotels and cinemas, in the less accessible parts, off the rail and main roads, tribes still exist as we knew them long ago: men and women nude, the only instrument of agriculture a pointed stick, and money in the form of coin still unknown. What has been the effect of the impact of the twentieth century on these relics of the stone age? This is the field of the new exploration of Africa, the field in which we need the assistance of the practical and constructive anthropologist.

As contact with modern civilisation must have a profoundly disruptive effect on the social organisation of a primitive society, and this effect is a continuing process, it is, therefore, essential for the anthropologist, administrator, and educator, in endeavouring to build foundations capable of bearing a permanent superstructure, to remember that they are dealing with a people in a period of social and intellectual transition. In other words, scientific research, in so far as it is concerned with practical work, must be directed to the African of the future rather than the African of the past or even as he is to-day, though an apprehension of both is essential for an understanding of the tendencies of the future.

Great changes have been brought about by the introduction of law and order and the suppression of slave-raiding. The concentration of the use of force into the hands of a central authority has pro tanto undermined the power and authority of the chief, and deprived the youth of Africa of its normal occupation of fighting and military service; while the suppression of war and slave-raiding has broken down the isolation of communities, so that the individual is able to offer his services as a wage labourer hundreds of miles away from his home. $\mathrm{He}$ has become acquainted with the conditions of life in an urban native quarter, and has acquired the command of money. This has also assisted in the spread of disease.

These are the inevitable effects of the white man's rule. When we come to the methods of applying that rule, there are two principles, generally known as assimilation and association.

The theory of assimilation would assign age-long tradition, customs, and beliefs to the scrap heap and substitute for them the modern forms of democracy, making the African a black European or black American. This system has been adopted by France in West Africa, but a growing body of opinion in

* Substance of a lecture by Lord Lugard, delivered on Sept. 24 at a joint meeting of Sections E (Geography) and $H$ (Anthropology) of the British Association.
France doubts the wisdom of this policy. An analogous system, though stopping short of miscegenation and conscription, known as 'direct rule', has been adopted widely in British dependencies. It is the system of which the results are now to be seen in India.

The alternative system of association works by devolution to native communities of the management of their own affairs, subject to the supreme authority of the governor and the law of the land. It recognises native institutions as the basis on which to build, and aims at their progressive improvement and adaptation to the changing conditions of Africa. Which of the two systems shall Africa in transition follow ? The answer brooks no delay. Great Britain must choose between the two systems, and on that choice the future of Africa depends. One thing is certain, that with the spread of education the African will not remain inarticulate.

Contact with the white man brings the African face to face at once with the fundamental conflict of conceptions between the communal outlook, upon which his life and actions have been framed, and the individualism taught by his dealing with the white man. His employer tells him his wages depend upon his individual exertions; the missionary tells him to obey the laws of God if he would save his own soul, and that tribal expiation will avail him nothing. These are new conceptions ; for his dominant characteristics are identification with his clan and belief in the presence and potency of the ancestral spirits of the tribe. Missionaries of long African experience believe that it is possible to engraft pagan rites on Christianity as they were in the early Church, while the Standing Advisory Committee of the Colonial Office has declared that what is good in the old sanctions and beliefs should be strengthened and retained. It is a problem that cannot be ignored. The new policy, too, in secular education will have a profound effect on the future of Africa.

The economic development of the resources of Africa is having an offect on African life, which is receiving intensive study by the International Institute of African Languages and Cultures. The access of wealth which has followed the opening up of Africa by road and rail, making possible the export of additional material produced by the extension and improvement of methods in agriculture, has greatly raised the standard of life.

It lies with us to see that the conclusions of science are rightly applied, and that the transition of the African from a lower to a higher standard of life and civilisation may be guided by a well-considered policy and scientific study, not only of the African as he used to be, but as he is to-day, and more especially of the tendencies which will operate to change him still more to-morrow.

\section{Control of Finance.}

$\mathrm{A}^{\mathrm{T}}$ $\mathrm{T}$ the recent meeting of the British Association, Mr. P. Barratt Whale read a paper to Section F (Economic Science and Statistics) on the Macmillan Committee's Report on Finance and Industry. This Report, he said, is as important to-day as when first printed, despite the crisis that has since occurred. The country no doubt will come through this crisis, and once more it will be necessary to operate the gold standard system, though it is desirable that this should be done on lines more satisfactory than in the im- mediate past. In the future, therefore, the Macmillan Report will be looked to for guidance.

The keynote of that Report is that currencies should be managed from the point of view of stabilisation of prices, and this is in accordance with the general trend of modern ideas in monetary science. It is, however, in marked contrast with the views which prevailed during the nineteenth century, when it was generally held that the gold value of the currency should remain unchanged. Now the main aim is to secure that the 
currency represents a definite standard of value in terms of its purchasing power, so that the price level can be stabilised. Stabilisation, however, may mean one of two things, and it will therefore be necessary to decide on the particular kind of stabilisation which is most desirable. Either the level of commodity prices as measured by the wholesale index number can be stabilised, or allowances can be made for changes in productive conditions which may imply variations in general prices not needed to be corrected by a process of stabilisation.

The first type of arrangement aims at complete stability in commodity prices, while the second would allow some variation in prices, so far as that variation should be attributed to general changes in productive conditions. Mr. Whale considers that the Macmillan Committee was justified in shirking a choice between these two methods, but a choice will have to be made and it is important for economists to determine what kind of stabilisation is most desirable. Currency systems will require to be managed by the central banks with, much greater freedom than hitherto.

Restrictions which have existed in the past have proved harmful, since they have generally operated to lock up gold. It is not enough for the central banks to control the domestic situation only, as against the influences of the other banks in the country ; the gold standard also implies that the currencies of the different countries should move together and have a closely related balance. There should thus be common aims and a common policy for all the central banks of the world. The Report took the view that the existing unequal distribution of the world's gold supply is not a cause but rather the result of causes-namely, the definite intention of France and the United States to accumulate gold. But there is another view which the Committee did not put forward, and that is that the accumulations of gold might not have been deliberately acquired by these countries but might have flowed as a result of the balance of international payments.

On this view the fundamental cause was the unbalanced state of indebtedness. The remedy, if this be the cause, is that France and the United States should either lend more abroad or should import more goods. Mr. Whale considers that the Committee has failed to give sufficient emphasis to the importance of price adjustments in balancing indebtedness. Both France and the United States have refused to allow a rise in their internal price levels, but if this had been permitted it would have facilitated imports into these countries from the rest of the world.

The Macmillan Report represents a combination of the ideas of the currency school with those of the banking school. The latter insists on the need for elasticity in currency arrangements, while the former emphasises the necessity of strict regulation of currency. Control, however, should be exercised by the central banks, so as to secure stability in the price level. The Report is on the right lines, but it is clear that in many respects the ideas of the Committee require to be worked out in detail, and some of its fundamental assumptions might be challenged.

\section{The Unit of Atomic Weight.}

$\mathrm{D}^{\mathrm{I}}$ SCUSSING the unit of atomic weight before Section A (Physics) at the meeting of the British Association in London on Sept. 28, Dr. F. W. Aston contrasted the point of view of the physicist and the chemist. The painstaking research in recent years to determine whether the atomic weights of complex elements vary with their origin and to effect the separation of isotopes has proved conclusively that for practical purposes variation in Nature is negligible, and has justified the decision of the Committee of the International Union of Chemistry to retain the old relative meaning of the words 'element' and 'atomic weight'. There is little reason to alter the present unit of atomic weight, $\mathrm{O}=16$, which has figured so long in chemical literature.

The physicist, on the other hand, is interested in the actual weights of the atoms, and it is only in the last twenty years that any comparison of the actual weights of the individual atoms has been possible. The original parabola method of Sir J. J. Thomson was followed by the first mass-spectrograph, in 1919, with a resolving power of 1 in 130 and an accuracy of about $0 \cdot 1$ per cent. With few exceptions, atomic weights deduced from mass-spectra agreed well with those generally accepted. The second mass-spectrograph, built in 1925, with a resolving power of 1 in 500 and an accuracy attaining 0.01 per cent, permitted the calculation of the percentage deviation of weight of an atom from a whole number on the scale of $\mathrm{O}^{16}=16$. During the last three years a valuable check on chemical calculations has been provided in a photometric method of calculating the relative abundance of isotopes from the intensity of their lines on mass spectra, which has been used to determine the mean atomic weights of complex elements.

After discussing Giauque and Johnston's announcement that observations on oxygen band spectra indicate the presence of $\mathrm{O}^{17}$ and $\mathrm{O}^{18}$, requiring alternatives to oxygen as our standard, Dr. Aston stated that he is in favour of retaining the present chemical scale unaltered. For most practical operations the chemist only requires a list of numbers, accepted internationally and guaranteed to within $0 \cdot 1$ per cent of the true atomic weights. For the fundamental requirements of physics the neutral atom of oxygen 16 appears to be the best standard, being the most convenient for work with band spectra and mass spectra. The 0.01 to 0.02 per cent difference in the two scales is not serious, and the meaning underlying the chemical scale differs so completely from that underlying the physical that confusion can easily be avoided by speaking of 'the atomic weight of chlorine' on one hand and 'the weight of the atom of chlorine 35 ' on the other.

\section{The Greenland Cod.}

IN the recently published report of the Northwestern Area Committee of the International Council for the Exploration of the Sea, ${ }^{1}$ much interesting and valuable information is brought together on the natural history and biology of the Greenland cod (Gadus callarias). This fish appears every year in Greenland waters, but its numbers are subject to most violent and sudden fluctuations.
About the year 1820, the date of the earliest available records, cod were present in enormous numbers in the Julianehaab district, and even so far north as Disco Bay. Thereafter they disappeared from all but certain fiords and sounds in the vicinity of Sarfânguak and Fiskenaesset in the south-west for roughly a quarter of a century. During the period 1845-49 they were back again in large numbers, but

No. 3234, VoL. 128] 